\title{
sciendo
}

\section{Using FCAW with Electrodes Based on Fe-Ti-Mo-B-C \\ System for Increasing of Durability \\ of Junk Removal Tools}

doi:10.2478/mape-2021-0012

Date of submission to the Editor: 04/2021

Date of acceptance by the Editor: 06/2021

MAPE 2021, volume 4, issue 1, pp. 132-141

\section{Olexandr Ivanov}

ORCID ID: 0000-0003-4678-7956

Ivano-Frankivsk National Technical University

of Oil and Gas, Ukraine

\section{Pavlo Prysyazhnyuk}

ORCID ID: 0000-0002-8325-3745

Ivano-Frankivsk National Technical University of Oil and Gas, Ukraine

\section{Liubomyr Romanyshyn}

ORCID ID: 0000-0002-4936-4943

Ivano-Frankivsk National Technical University of Oil and Gas, Ukraine

\section{Taras Romanyshyn}

ORCID ID: 0000-0002-0856-1537

Ivano-Frankivsk National Technical University of Oil and Gas, Ukraine

\section{Yurii Mosora}

ORCID ID: 0000-0002-3192-7146

Ivano-Frankivsk National Technical University of Oil and Gas, Ukraine

\section{INTRODUCTION}

Restoring wear parts of machines and equipment is extremely important, perspective and, in many occasions, much more economically-effective than buying or producing new parts, especially in such industries as fuel industry, oil and gas industries, woodworking, etc. The peculiarity of the equipment of these industries is that they often work in intensive contact with abrasive and aggressive environments within high working pressures and cyclic loads (Badisch and Miller, 2003). The other feature of such equipment, is the fact that wear occurs only in small areas which are actually contact with abrasive masses or aggressive environment. The result of such working conditions causes wear losses only small volume of parts/equipment comparing to the volume of whole part. The common way for increasing the working efficient of equipment application on working surfaces of coating with increased wear-resistance or restoring of working surfaces with using of such wear-resistance material.

Variety and versatility of coating methods allow to choose the method depending on required performance, materials, speed, surface quality, etc. Among the variety of such methods most frequently used because of their high efficiency are hardfacing methods such as Shielded metal arc welding (SMAW), Flux- 
cored arc welding (FCAW), Gas tungsten arc welding (GTAW), and laser cladding. Comparing these methods, FCAW can provide the higher surface quality than SMAW and more productivity than GTAW and laser cladding. Also, the volume of deposited hardfacing material with using of FCAW is higher than it in SMAW, GTAW or laser cladding.

Most of researchers that aim their investigation of the FCAW tungsten-free systems for obtaining wear-resistance surfaces are using systems based on FeCr-C (Wang and Li, 2010, Tang et al., 2011, Yuan et al. 2011) or Fe-Ti-C (Wang et al., 2008, Correa et al., 2007, Zhang et al., 2018, Gao et al., 2016, Lin et al., 2011) with additions of some metals from IV-VI group of the periodic table of elements.

Materials based on Fe-Cr-C are characterized with high hardness but such hardness is achieved because of structure that consist with coarse prolonged $\mathrm{Me}_{7} \mathrm{C}_{3}$ type chromium carbides ( $\left.13 \mathrm{GPa}\right)$ and $\mathrm{Fe}(\mathrm{Cr})+\left(\mathrm{Me}_{7} \mathrm{C}_{3}\right)$ type eutectic with low crack resistance. On the other hand, in the case of materials based on Fe-Ti-C, hard titanium carbides ( $30 \mathrm{GPa}$ ) are extra fine size, which leads to their exclusion with the rest of material during the abrasion wearing. For solving such problems, and achieving increased hardness and crack resistance of materials scientists are also experimenting with alloying above mentioned systems with boron, $\mathrm{Nb}, \mathrm{V}$ and Mo. Mostly metals for researching are used in form of ferroalloys, but there are works that aimed on using pure metal powders to achieving structures with increased mechanical parameters, that are characterized with higher wear resistance (Ivanov et al., 2020).

Restoring and increasing of durability of tools and equipment parts is one of the most important ways to improving the efficiency of production industries. Using cheaper materials with increased mechanical parameters and wear resistance leads to increasing the time between overhauls (TBO). It is extremely important in oil and gas industry, especially while drilling or servicing the borehole. Because of complexity of drilling operations caused by necessity of lifting the whole drilling column for changing the drilling bits, expensive materials based on tungsten carbide are used for hardfacing of drilling bits. Other example is the junk removal tools used for drilling and workover operations. Junk refers to any objects or debris which have been dropped into or lost in the borehole. Junk can include all manner of things, from downhole tools and bottomhole assembly components, to drilling bit cones. Beside that, junk removal operations are often carried out in conditions of abrasion wearing, when the particles of drilled rocks contact with junk removal instrument, also, in some cases, it is easier to break an object into smaller pieces than to retrieve it whole. Junk mills attached to removal tools are used for such operations (DrillingFormulas.com, 2018). Such instruments and tools work under cyclic loads in conditions of intense abrasion wear. In this case, abrasion wear is a combination of two mechanisms - contact of working surface with fixed and non-fixed abrasive.

In the present investigation the aim was to develop the flux-cored electrodes that provides a surface with high hardness (> 60 HRC) that could be used for 
increasing the durability of tools/parts of equipment that works in environment with intensive abrasive wear, increased working pressures and cyclic loads.

\section{METHODOLOGY OF RESEARCH}

The powder electrodes were made by rolling the initial mixture of powder components into steel tape on the rolling mill (Fig. 1). As a steel tape low carbon steel $08 \mathrm{kp}$ (GOST 503-81) was used. Amount of powder that fills the steel shell is controlled by the charge regulator (Fig. 1, 3), which provides the possibility of changing the correlation between amount of steel and powder i.e. the chemical composition of electrode wire. Cutting rolls (Fig. 1,8) provides cutting of electrode wire to electrodes with length of $420 \mathrm{~mm}$.

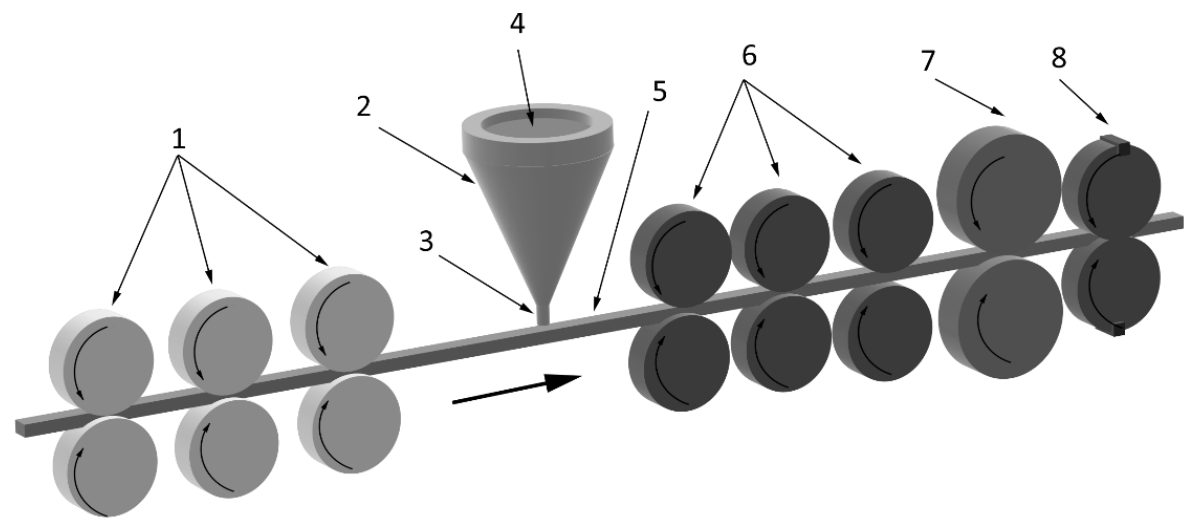

Fig. 1 Schematic drawing of the electrode wire rolling mill (1 - deforming rolls;

2 - bunker with flux powder; 3 - charge regulator; 4 - flux material; 5 - steel wire; 6 - wire closing rolls; 7 - leading rolls; 8 - cutting rolls)

Raw materials for investigation were fine powders of Ti (PTH grade TU 48-1078-83), Mo (MPCh grade TU 48-19-316-80) and B4C (TU 95.960-82). The mass fraction of each specimen shown in Table 1.

Table 1 Nominal chemical composition of initial components

\begin{tabular}{|c|c|c|c|}
\hline \multirow{2}{*}{$\begin{array}{c}\text { Specimen } \\
\text { No. }\end{array}$} & \multicolumn{3}{|c|}{ Compositions, wt.\% } \\
\cline { 2 - 4 } & $\mathrm{B}_{4} \mathrm{C}$ & $\mathrm{Ti}$ & $\mathrm{Mo}$ \\
\hline 1 & 27.78 & 72.26 & - \\
\hline 2 & 21.54 & 33.585 & 44.88 \\
\hline
\end{tabular}

For determining the correlation between powder filler and steel shell the filling coefficient $\left(K_{f}\right)$ formula $(1)$ was used:

$$
K_{f}=100-\frac{W_{E} \cdot 100}{W_{O}},
$$

where:

$W_{E}$ - weight of filled electrode,

$W_{O}$ - weight of empty electrode.

Weight of empty electrode is $28.5 \mathrm{~g}$, control of the filling coefficient $K_{f}$ was carried out with weighing accuracy of $0.01 \mathrm{~g}$, by weighing three electrodes of each specimen. 
In present study filling of electrodes with powder $\left(K_{f}\right)$ was approximately $30 \%$, and the calculated chemical composition for each specimen shown in Table 2.

Table 2 Nominal compositions of sample wires

\begin{tabular}{|c|c|c|c|c|}
\hline \multirow{2}{*}{$\begin{array}{c}\text { Specimen } \\
\text { no. }\end{array}$} & \multicolumn{4}{|c|}{ Compositions, at.\% } \\
\cline { 2 - 5 } & $\mathrm{B}_{4} \mathrm{C}$ & $\mathrm{Ti}$ & $\mathrm{Mo}$ & $\mathrm{Fe}$ \\
\hline 1 & 29.05 & 17.39 & - & bal. \\
\hline 2 & 27.6 & 8.25 & 8.26 & bal. \\
\hline
\end{tabular}

SNOL-type drying cabinet was used to assure the dryness of the initial powder component at $120^{\circ} \mathrm{C}$ for $1 \mathrm{~h}$ before weighing and additionally for $1.2 \mathrm{~h}$ after mixing to prevent influence of air humidity on bulk properties. Mixing of powder components was performed on a laboratory gravity drum mixer for $1.5 \mathrm{~h}$.

Experimental hardfacing was carried out on a substrate of steel 45 (GOST 10502013) by manual FCAW with welding parameters of 150 A direct current and 30 $\mathrm{V}$ voltage with a reverse polarity using VDU-506 rectifier. Cooling was carried out on air at a temperature $20^{\circ} \mathrm{C}$.

ZEISS EVO 40XVP electron microscope was used for scanning electron microscopy (SEM) to observe a microstructure of specimen hardfacings. Hardness of specimens was measured by means of the average measurements taken from top surface of the harfacing layers by Rockwell method, using TK-2 hardness meter (scale "C").

To ensure the complex analysis of wear resistance of hardfacings abrasion tests were carried out in condition of fixed abrasive and condition of non-fixed abrasive. Wear testing with fixed abrasive was carried out at room temperature using the MT-1 wear testing machine, as presented in Fig. 2.

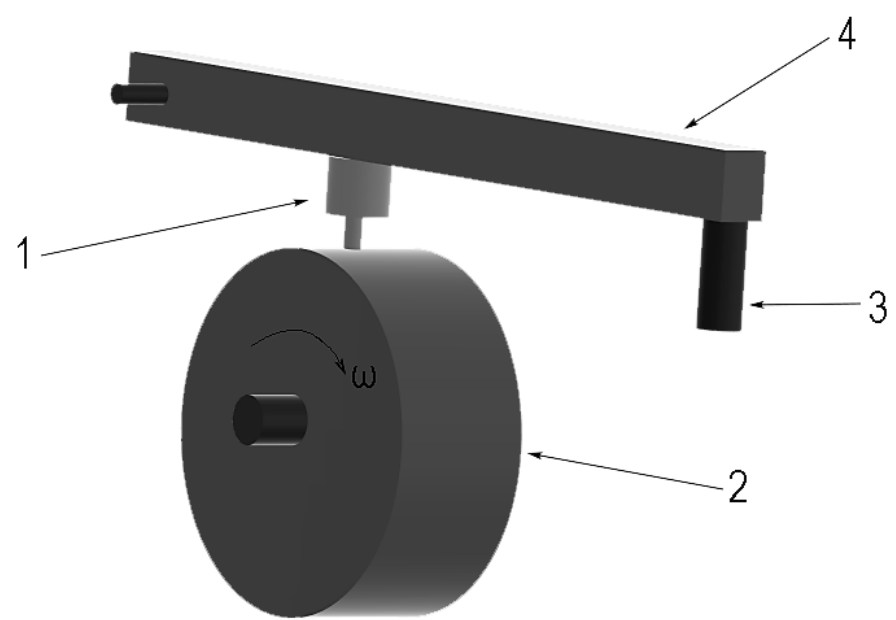

Fig. 2 A schematic diagram of wear testing in condition of fixed abrasive (1 - specimen; 2 - abrasive wheel; 3 - weight; 4 - lever)

Test specimens were machined as cylinders with radius of $10 \mathrm{~mm}$. As a wear ring was used silicon carbide ring of $64 \mathrm{C}$ F46 L 7 grade with $300 \mathrm{~mm}$ diameter. Contact load of specimen and ring was $100 \mathrm{~N}$, sliding speed of $2 \mathrm{~m} / \mathrm{s}$ and sliding 
distance of $400 \mathrm{~m}$. Wear testing with non-fixed abrasive was carried out at room temperature according to the GOST 23.208-79 using testing equipment (Fig. 3).

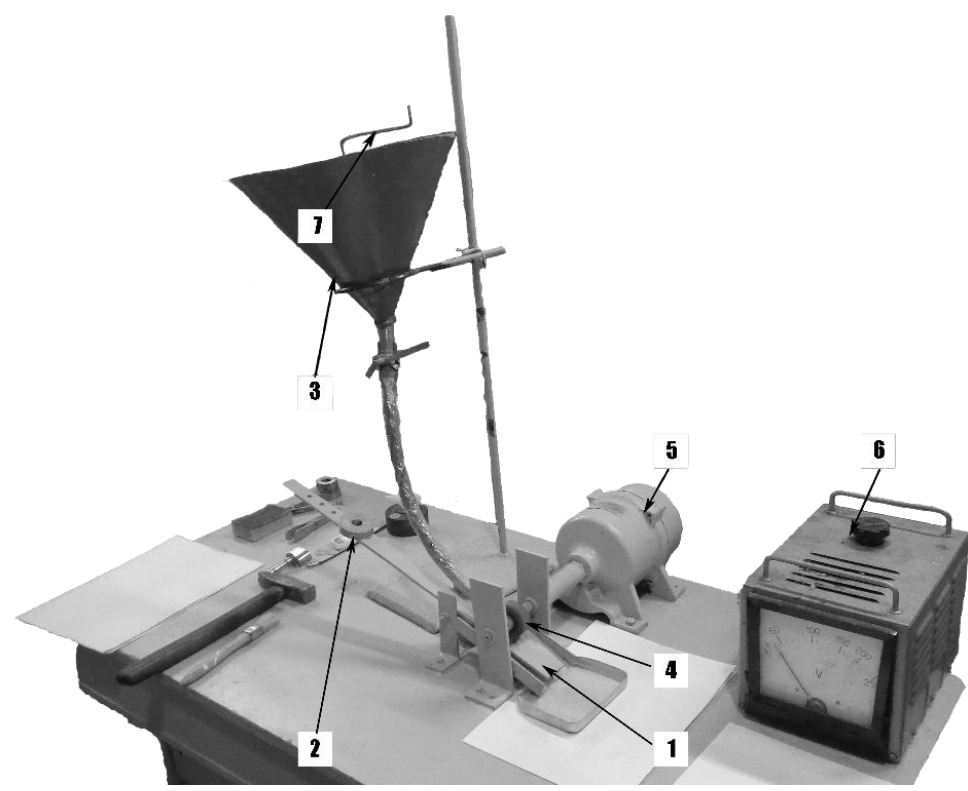

Fig. 3 Testing equipment for wear testing in condition of non-fixed abrasive (1 - specimen; 2 - weight; 3 - bunker for abrasive material; 4 - rubber wheel; 5 - motor; 6 - speed control device; 7 - abrasive material dosage regulator)

As abrasion material $\mathrm{SiO}_{2}$ abrasion powder with grain size of $0.2-0.4 \mathrm{~mm}$ was used in both tests. Contact load of specimen and rotation wheel was $3 \mathrm{~N}$, rotation speed converted into linear $0.5 \mathrm{~m} / \mathrm{s}$, test time $220 \mathrm{~s}$. Amount of wear was measured as a mass difference between specimens before and after testing. Wear losses was measured with weighing accuracy of $0.01 \mathrm{~g}$.

\section{RESULTS}

Microstructure of specimen 1, as can be seen on Fig. 4, consist of small grains of TiC with a size around of $5 \mu \mathrm{m}$, distributed in the dark colored phase that can be described as ferrite. Beside ferrite and titanium carbide, there is eutectic, based on ferrite and iron boride $\mathrm{Fe}_{2} \mathrm{~B}$.

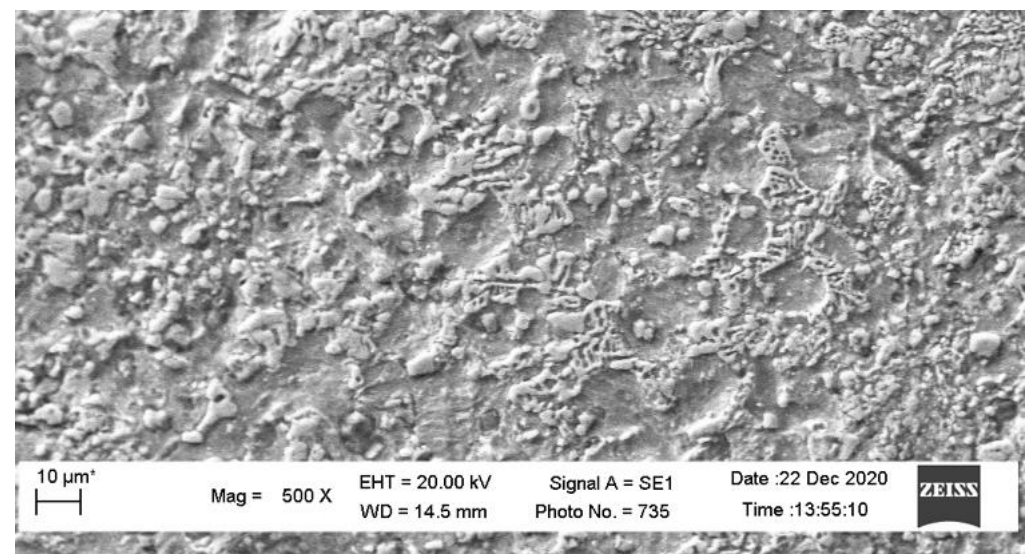

Fig. 4 SEM analysis of the microstructure of FCAW coating of specimen 1 
Microstructure of the specimen 2 (Fig. 5) differs a lot. Addition of Mo in the chemical composition of electrode significantly affects on the structure. Still, there are ferrite phase and eutectic based on ferrite and $\mathrm{Fe}_{2} \mathrm{~B}$, but the new phase can be seen in form of bright colored cubic-shaped grains $(\sim 10 \mu \mathrm{m})$, that can be described as $\mathrm{Mo}_{2} \mathrm{FeB}_{2}$. It can be seen, that there are small dark grains in the centers of $\mathrm{Mo}_{2} \mathrm{FeB}_{2}$ grains. Such grains are the $\mathrm{TiC}$, which work as modifiers and provides the formation of uniformly distributed equiaxial grains of $\mathrm{Mo}_{2} \mathrm{FeB}_{2}$ in the structure of hardfacing.

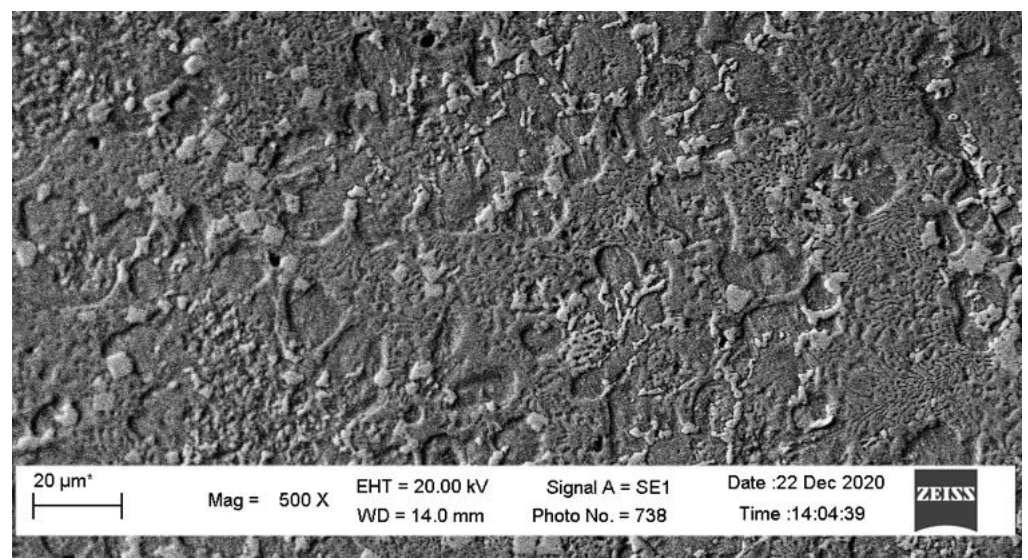

Fig. 5 SEM analysis of the microstructure of FCAW coating of specimen 2

For comparing the abrasion resistance of researched electrodes few serial materials were chosen. Beside researched specimens hardfacings based on Fe-Cr-Mo-Mn-Si-C (Hardalloy 155), Fe-Cr-Mn-C (Weartrode 60T) and WC (RDWC 076) systems were tested. Fig. 6, a and Fig. 6, b shows results of abrasive wear tests on non-fixed and fixed abrasive, accordingly.

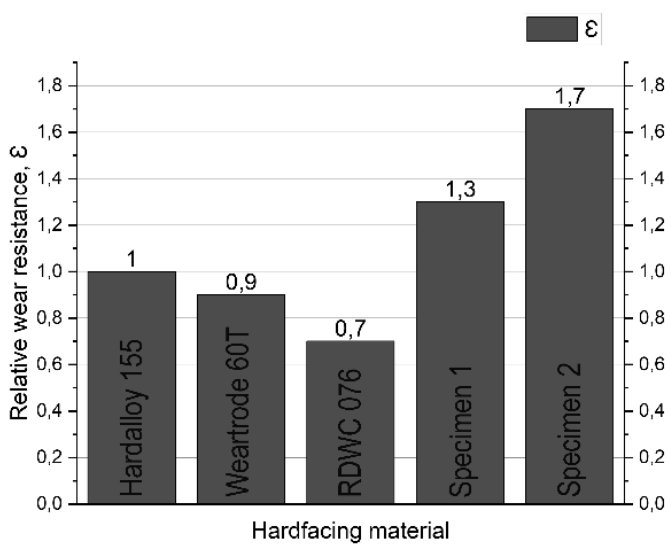

a)

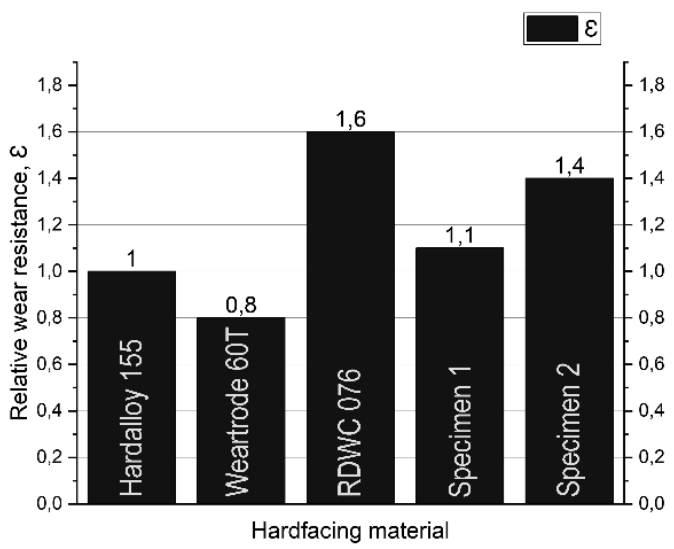

b)

Fig. 6 Dependence of relative wear resistance $\varepsilon$ in condition of non-fixed (a) and fixed (b) abrasive

It can be seen that researched hardfacings are given in lower wear level in the condition of non-fixed abrasion among tested serial materials, but also slightly higher wear level in condition of fixed abrasion than tungsten-carbide based RDWC 076 material. Despite that, researched specimens, based on Fe-Ti-Mo- 
B-C system shows higher wear resistance in condition of fixed-abrasive than serial materials based on Fe-Cr-C system. Hardness of specimen 1 is $56 \mathrm{HRC}$ and hardness of specimen 2 is $63 \mathrm{HRC}$.

Despite the fact, that tungsten-based material showed the higher wear resistance in condition of abrasive wear with fixed abrasive, investigated materials showed higher wear resistance in condition of non-fixed abrasive.

The industrial approbation of specimen 2 was carried out by hardfacing of working surfaces of junk mill (Fig. 7) which is attached to the magnet fishing tool and is the part of borehole junk removal tool (Fig. 8). Junk mills work under the conditions that is a combination of wearing with fixed and non-fixed abrasive, with a contact of aggressive fluids, drilled rocks and parts of tools if there are any losses in the borehole.

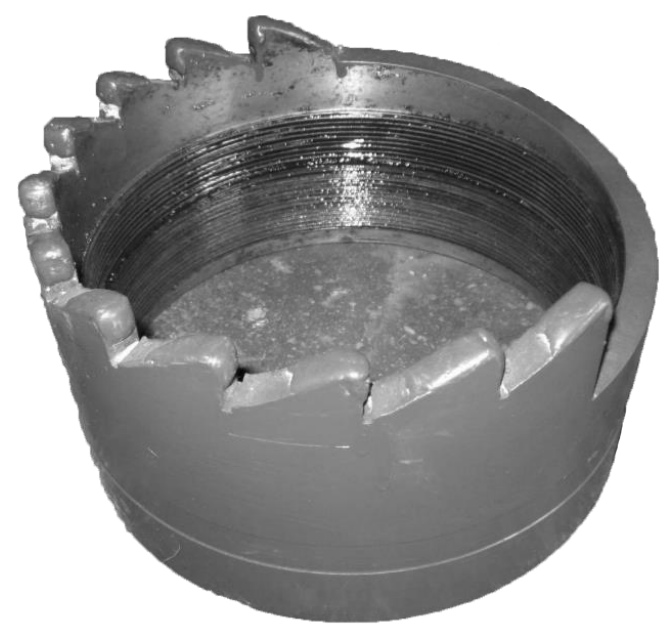

Fig. 7 General view of junk mill with hardfaced and painted working surface

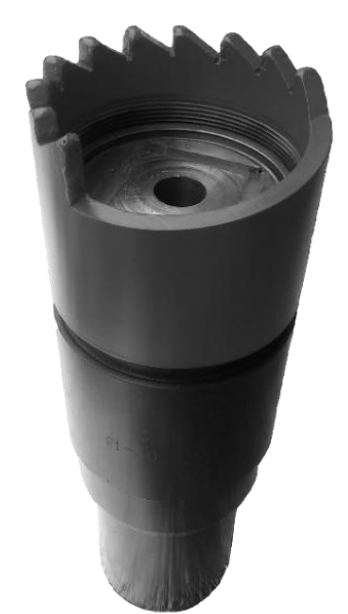

Fig. 8 Junk mill attached to the magnet fishing tool

If drilling bit cones mostly contact with fixed abrasive while drilling the borehole, junk removal tools and junk mills mostly contact with non-fixed abrasive while junk removal operations, because they work with the remains of the drilled rock, so there is a sense in using the materials with higher resistance to abrasion on 
non-fixed abrasive, than to abrasion on fixed abrasive. It is also important that researched materials are cheaper than materials based on tungsten carbide. The medium height of the deposited layer of proposed materials is $2 \ldots 3 \mathrm{~mm}$ with a possibility to deposit up to 3 layers, so it can be used for restoring the geometry of equipment parts as well as increasing their durability.

The held probation showed increasing of the TBO period of junk mills for magnet fishing tools by 1.5...1.6 times compared to the junk mills hardfaced with serial materials based on tungsten carbides.

\section{DISCUSSION}

Analyzed equipment of oil and gas industry, such as junk removal tools that works in condition of intensive abrasion wear within increased working pressures and cyclic loads and in contact with aggressive fluids. Such conditions are the reasons of short TBO period for such tools. Usually, working surfaces of these tools are restored by FCAW with materials based on tungsten. But also, for junk mills working conditions can be described as combination of wearing with fixed and non-fixed abrasive. Tungsten-based materials consist of coarse hard tungsten carbides distributed in relatively soft matrix it shows high durability under conditions of wearing with fixed abrasive because coarse carbides contact with abrasive material which is confirmed by testing (Fig. 6b). But under conditions of non-fixed abrasive - abrasive particles wear the soft matrix of tungsten-based materials which cause that the coarse grains of tungsten carbide stick out from material and thus they are exclude from matrix due to weak coherence with it. At the other hand, researched materials based on FeTi-Mo-B-C system showed higher resistance under conditions of wearing with non-fixed abrasive. It can be the result of the structure of material (specimen 2) which consist of cubic-shaped grains of $\mathrm{Mo}_{2} \mathrm{FeB}_{2}$ that form around small grains of $\mathrm{TiC}$, which forms at high temperature and work as a modifier. $\mathrm{Mo}_{2} \mathrm{FeB}_{2}$ are uniformly distributed in the structure that consist also of eutectic based on $\mathrm{Fe}_{2} \mathrm{~B}$ and ferrite and small amount of ferrite. Such structure is a result of using pure metal powders instead of using ferroalloys as initial component. Thus, the addition of Mo to the Fe-Ti-B-C system leads to the formation of new phase in form of cubic grains that form around modifiers and such materials are characterized with increasing of hardness to $63 \mathrm{HRC}$ comparing to $56 \mathrm{HRC}$ in the Fe-Ti-B-C system. Due to this, the TBO period of junk mills that were hardfaced with researched material was increased in 1.5...1.6 times.

According to the results of the bench tests and approbation in real working conditions, the developed material of Fe-Ti-Mo-B-C system can be recommended for strengthening parts and tools of technological equipment that works in condition of wearing with non-fixed abrasive with increased working pressures and cyclic loads as an alternative to the traditional electrodes based on Fe-Cr-C system as well as an expensive materials based on $\mathrm{W}, \mathrm{Nb}$ or $\mathrm{Co}$. Further tests of the developed materials on working elements are desire. Investigation of proposed Fe-Ti-Mo-B-C system with higher filler coefficient, 
which can lead to the higher concentration of carbides and borides in structure, can be done.

\section{CONCLUSION}

Working conditions of tools of equipment for junk removal operations while drilling and workover operations were analyzed.

Using of pure metal powders in researched materials (specimen 2) while FCAW led to the formation of hard structure $(63 \mathrm{HRC})$ with uniformly distributed fine grains of $\mathrm{Mo}_{2} \mathrm{FeB}_{2}$, that forms around $\mathrm{TiC}$ which works as modifiers. Such structure showed the highest wear resistance under condition of non-fixed abrasive among the other tested materials and high wear resistance under condition of fixed abrasive, higher than materials based on $\mathrm{Fe}-\mathrm{Cr}-\mathrm{C}$ systems. As a result, investigated electrode material (specimen 2) was used for increasing a wear resistance of junk mills that are a part of junk removal tools.

Using of proposed electrode materials based on Fe-Ti-Mo-B-C system leads to improvement of durability and increasing the TBO period of junk removal mills that is a part of junk removal tools used for drilling and workover operations compared of serial tungsten-based electrodes.

\section{REFERENCES}

Badisch, E. and Miller, C. (2003). Abrasive wear of high speed steels: influence of abrasive particles and primary carbides on wear resistance. Tribology International, 36, pp. 765-770.

Wang, Q. and Li, X. (2010). Effects of $\mathrm{Nb}, \mathrm{V}$ and $\mathrm{W}$ on Microstructure and Abrasion Resistance of Fe-Cr-C Hardfacing Alloys. Welding Journal, 89(7), pp. 133-139.

Tang, W.B. et al. (2011). The Effect of Microstructure on Properties of Fe-Cr- $\mathrm{Nb} / \mathrm{Ti}$ Hardfacing Alloy. Advanced Materials Research, 279, pp. 126-131.

Yuan, T. et al. (2011). Optimal Design for Fe-Cr-C Hardfacing Alloys with Anti-Wearing. Advanced Materials Research, 189-193, pp. 3545-3548.

Wang, X-h. et al. (2008). Microstructure of the Fe-based hardfacing layers reinforced by TiC-VC-Mo2C particles. Surface and Coating Technology, 202 (8), pp. 15021509.

Correa, E. et al. (2007). Development of an Iron-Based Hardfacing Material Reinforced with Fe-(TiW)C Composite Powder. Metallurgical and Materials Transactions A, 38(5), pp. 937-345.

Zhang, M. et al. (2018). Effect of Molybdenum on the Wear Properties of (Ti, Mo)C$\mathrm{TiB}_{2}-\mathrm{Mo}_{2} \mathrm{~B}$ Particles Reinforced Fe-Based Laser Cladding Composite Coatings. Journal of Tribology, 140(5): 051603.

Gao, W. et al. (2016). Effect of a small addition of Ti on the Fe-based coating by laser cladding. Surface and Coating Technology, 291, pp. 423-429.

Lin, T. et al. (2011). SHS-TiC Particle Reinforced Hardface Coating Prepared by Vacuum Cladding Process. Advanced Materials Research, 418-420, pp. 932-935.

Ivanov, O. et al. (2020). Improvement of Arbasion Resistance of Production Equipment Wear Parts by Hardfacing with Flux-Cored Wires Containing Boron Carbide/Metal Powder Reaction Mixtures. Management Systems in Production Engineering, 28 (3), pp. 178-183.

DrillingFormulas.com, (2018) Junk Removal Tools Used for Drilling and Workover Operation [online] Available at: https://www.drillingformulas.com/junk-removal-toolsused-for-drilling-and-workover-operation/ [Accessed 20 Apr. 2021]. 
Abstract: In this work were analyzed factors and working conditions that leads to the wearing of junk mills tools that are a part of junk removal equipment used in drilling and workover of borehole. Such equipment is a part of oil and gas industry and work under condition of intense abrasive wearing with increased pressures and cyclic loads. Was established that traditional hardfacing materials based on the $\mathrm{Fe}-\mathrm{Cr}-\mathrm{C}$ system are not effective for improvement of abrasion resistance of elements of such equipment due to their low crack resistance and low hardness of chromium carbides. The aim of this work was to increase a durability of that equipment by using of flux cored electrodes with reaction components of pure metal powders, which leads to forming the fine-grained structure with increased hardness. Powders of $\mathrm{Ti}, \mathrm{Mo}, \mathrm{B}_{4} \mathrm{C}$ and their combinations were used. Structures of the hardfacing coatings were investigated by method of metallography, scanning electron microscopy (SEM). Abrasion wear tests were held under condition of fixed and non-fixed abrasion. Using of pure metal powders led to formation of a fine-grained structure with grains of $\mathrm{Mo}_{2} \mathrm{FeB}_{2}$ that forms around $\mathrm{TiC}$, which work as modifier. It was investigated that the researched material based on Fe-Ti-Mo-C-B system that was used for increasing the wear resistance of junk mills led to increasing of the TBO period in 1.5-1.6 times comparing with serial hardfacing materials based on tungsten.

Keywords: abrasion resistance, flux cored electrodes, hardfacing, junk mills, microstructure 